\title{
La historicidad de la crítica. Un esbozo de la cuestión*
}

\author{
The historicity of critique. A sketch of the question
}

\author{
JOSÉ MANUEL ROMERO CUEVAS *** $^{*}$
}

\begin{abstract}
Resumen: El presente artículo se ocupa del significado de la historicidad para el concepto de crítica social y para la propia teoría crítica. Comienza discutiendo el estatuto ontológico que la tradición de pensamiento hermenéutico otorgó a la noción de historicidad, mostrando su problematicidad filosófica y política. A continuación desarrolla las implicaciones y los retos que para la labor crítica supone la asunción de su propia historicidad concreta. La tesis que se defiende aquí es que el alcance y la profundidad de la crítica se ponen en juego en el modo en que logra apropiarse con radicalidad su carácter histórico.

Palabras clave: Historicidad, Crítica, Teoría Crítica, Filosofía política.
\end{abstract}

\begin{abstract}
The present article is concerned with the meaning of the historicity for the concept of social critique and for critical theory itself. It begins with a discussion of the ontological statute the tradition of hermeneutical thinking conferred to the notion of historicity and shows its problematic philosophical and political consequences. The article continues in explaining the implications and the challenges the assumption of its concrete historicity involves for the critique. My contribution argues that the range and depth of the critique depend on the way it achieves a radical appropriation of its historical character.
\end{abstract}

Key Words: Historicity, Critique, Critical Theory, Political Philosophy.

La problemática de las bases normativas de la crítica social se planteó con plena reflexividad en el seno de lo que se ha denominado la Teoría Crítica de la Escuela de Frankfurt, es decir, en el trabajo de ese grupo de intelectuales conformado principalmente por Max Horkheimer, Herbert Marcuse y Theodor W. Adorno. ${ }^{1}$ Ya el artículo programático de Horkheimer «Teoría tradicional y teoría crítica», publicado en 1937, afrontaba esta cuestión ${ }^{2}$ y la influyente obra de Marcuse El hombre unidimensional, de 1964, comenzaba diagnosticando

Fecha de recepción: 07/10/2012. Fecha de aceptación: 07/07/2013.

* Este artículo ha sido realizado en el marco del proyecto de investigación «Las bases normativas de la crítica en un marco global y plural» (FFI2010-15065), financiado por el Ministerio de Ciencia e Innovación.

** Profesor de la Universidad de Alcalá (josemanuel.romero@uah.es). Sus líneas de investigación son Hermenéutica, Teoría Crítica y Filosofía Social. Es autor de Crítica e historicidad, Barcelona, Herder, 2010 y editor de $H$. Marcuse y los orígenes de la teoría crítica, Madrid, Plaza y Valdés, 2010.

1 Adopto aquí esta denominación para caracterizar el planteamiento de estos autores porque ellos mismos la asumieron, sobre todo en los años sesenta. Ver R. Wiggershaus: La Escuela de Frankfurt, Buenos Aires, Fondo de Cultura Económica, 2010.

2 Horkheimer colocó en la base de la teoría crítica de la sociedad de matriz marxiana por la que abogaba entonces un interés, de carácter histórico-político, por la emancipación; ver M. Horkheimer: Teoría tradicional y teoría crítica, Barcelona, Paidós, 2000. 
una «parálisis de la crítica» en las sociedades desarrolladas, unas sociedades carentes de oposión real, y se confrontaba explícitamente con el problema de las «bases de la crítica». ${ }^{3}$ En todos estos autores, la actividad crítica fue concebida como una praxis histórica, impulsada por un interés y unos juicios de valor históricos, aunque cabe especular en qué medida el último Horkheimer y Marcuse a lo largo de toda su trayectoria tendieron a ubicar el sustento último de la crítica en la base común que define a la humanidad, como es el caso del sentimiento de compasión ante el sufrimiento de los demás o de la idea de una esencia humana que las condiciones imperantes impiden realizar.

El autor que hizo de la cuestión de las bases normativas de la crítica social y de la teoría crítica de la sociedad el asunto central y expreso de su labor teórica fue un pensador que para muchos intérpretes debe ser ubicado en esta corriente de pensamiento de la teoría crítica, a saber, Jürgen Habermas. Lo característico de su posición desde finales de los años sesenta fue su giro desde una concepción de la normatividad de la crítica en términos históricos, rastreable en algunos de los materiales incluidos en sus obras Teoría y praxis y La lógica de las ciencias sociales, hacia un esfuerzo por explicitar a posteriori, mediante una reconstrucción racional, las condiciones universales y necesarias de la crítica en cuanto tal. Este proyecto teórico cuasi-trascendental, que se concretó en un principio en lo que Habermas denominó pragmática universal y luego en su teoría de la acción comunicativa, ha marcado el modo en que influyentes discípulos suyos, como A. Wellmer y sobre todo A. Honneth, se han confrontado con este problema. ${ }^{4}$

Sin embargo, en los últimos años se está produciendo entre los estudiosos de la problemática de la crítica, sobre todo en el círculo del Institut für Sozialforschung y de la Universidad de Frankfurt, un replanteamiento del enfoque cuasi-trascendental sobre las bases de la crítica social, ${ }^{5}$ replanteamiento que ha sido respaldado significativamente por el propio Honneth, que en el último periodo de su producción teórica se ha decantado abiertamente hacia un modelo de crítica inmanente que, a pesar de que aparece caracterizada por él como «reconstrucción normativa», implica un distanciamiento explícito de toda pretensión de tipo cuasi-trascendental. ${ }^{6}$ La objeción fundamental al enfoque formal cuasi-trascendental forjado

3 H. Marcuse: El hombre unidimensional, Barcelona, Ariel, 1984, pp. 19 y ss. Marcuse, en esta obra, planteó la cuestión de las bases de la crítica en términos de los juicios de valor implícitos en todo análisis social (y aquí cabría reconstruir una polémica de fondo con la distinción weberiana entre hechos y valores): en primer lugar, «el juicio que afirma que la vida humana merece vivirse» $\mathrm{y}$, en segundo lugar, «el juicio de que, en una sociedad dada, existen posibilidades específicas para un mejoramiento de la vida humana y formas y medios específicos para realizar esas posibilidades.» Ibid., pp. 20-1. Estos juicios de valor constituirían el horizonte normativo de partida de una aproximación crítica a la sociedad vigente.

4 La caracterización de los planteamientos de Habermas y Honneth a partir de la noción de recontrucción racional es realizada por M. Iser: Empörung und Fortschritt. Grundlagen einer kritischen Theorie der Gesellschaft, Frankfurt a.M., Campus, 2008, especialmente pp. 84-107 y 162-193.

5 Ver R. Celikates: Kritik als soziale Praxis, Frankfurt a.M., Campus Verlag, 2009; R. Forst, M., Hartmann, R., Jaeggi y M. Saar (eds.): Sozialphilosophie und Kritik, Frankfurt a.M., Suhrkamp, 2009; R. Jaeggi: Kritik von Lebensformen, Frankfurt a.M., Suhrkamp, 2013; R. Jaeggi y T. Wesche (eds.): Was ist Kritik?, Frankfurt a.M., Suhrkamp, 2009; M. Salonia: Walter Benjamins Theorie der Kritik, Berlín, Akademie Verlag, 2011; M. Saar: Genealogie als Kritik. Geschichte und Theorie des Subjekts nach Nietzsche und Foucault, Frankfurt a.M., 2007 y T. Stahl: Immanente Kritik. Elemente einer Theorie sozialen Praktiken, Frankfurt a.M., Campus Verlag, 2013.

6 Este modelo de crítica constituye el enfoque metodológico de su reciente obra Das Recht der Freiheit, Frankfurt a.M., Suhrkamp, 2011. 
por Habermas y que Honneth ha continuado durante una parte importante de su producción teórica es que no logra hacerse cargo de la historicidad, facticidad y perspectivismo de la praxis crítica real, al pretender sustentar la crítica singular en condiciones formal-ideales que serían presuntamente inherentes a la interacción humana y a la crítica misma. Tal estrategia acabaría abriendo un abismo entre las condiciones históricas, fácticas y perspectivistas de la crítica (que amenazan con contaminar la crítica de un particularismo que la incapacitaría para elevarse a la deseada universalidad) y sus condiciones ideales inherentes, que en Habermas quedan sintetizadas en la idea de una situación ideal de habla, la cual no puede dejar de ser anticipada por los hablantes en cada acto de habla pero al mismo tiempo tiene que servir de baremo crítico para la valoración de los contextos fácticos de interacción. ${ }^{7}$ Esta deriva hacia un enfoque que se desentiende de la historicidad, facticidad y perspectivismo de la crítica como un ámbito problemático que constituye una amenaza para la pretensión de validez universal de la crítica social acaba significativamente articulando una concepción de la crítica también formal, a saber, una crítica que contrapone la situación ideal de habla a los contextos de interacción concretos, crítica que es ciertamente capaz de cuestionar modos de opresión tan dolientes como la desigualdad de género y el autoritarismo político pero carece de herramientas para cuestionar por ejemplo las formas de opresión económica propias del capitalismo desarrollado ${ }^{8}$.

El presente trabajo se enmarca en este esfuerzo en marcha de problematización de la aproximación cuasi-trascendental a las bases de la crítica. Dejando atrás este enfoque, pretende confrontarse directamente con la cuestión de la historicidad de la crítica, con objeto de valorar si tal historicidad supone una amenaza para la consistencia y alcance de la actividad crítica o si, en cambio, bien entendida, cumple un papel productivo en la misma. Para realizar esta tarea, resulta quizá adecuado comenzar por atender aunque sea de manera somera a la corriente contemporánea de pensamiento que de manera más intensa se ha ocupado de la cuestión de la historicidad, a saber, la hermenéutica, centrándonos sobre todo en la obra del primer M. Heidegger (se efectuarán además breves referencias a la obra de H.-G. Gadamer). Con ello se pretende, sin voluntad de exhaustividad, exponer un modo determinado y muy influyente de afrontamiento de la temática de la historicidad y valorar si es adecuado para reflexionar sobre la historicidad de la propia crítica. Se va a mostrar que, a pesar del llamado de la hermenéutica a hacerse cargo de la propia historicidad, su enfoque afronta la historicidad fundamentalmente en términos ontológicos. Esto marca las distancias con la tradición de la teoría crítica, que ha percibido en toda postulación de determinados factores como ontológicos, ya sea en el ser humano como en la sociedad, una naturalización de lo histórico de consecuencias perversas tanto en el plano político como en el moral (I). Lo propio de la teoría crítica va a ser en cambio el hacerse cargo, a través de un ejercicio de autorreflexión, de su historicidad concreta, lo cual va a implicar asumir el carácter histórico de su objeto, de la propia teoría, de la situación del crítico y de sus propios parámetros normativos (II). Naturalmente, una concepción tal de la

7 Ver J. Habermas: Teoría de la acción comunicativa: complementos y estudios previos, Madrid, Cátedra, 1989, pp. 154 y ss. y, del mismo autor, El discurso filosófico de la modernidad, Madrid, Taurus, 1989, pp. 382 y ss.

8 Me ocupo de esta cuestión en mis trabajos «J. Habermas, A. Honneth y las bases normativas de la teoría crítica», en Constelaciones. Revista de Teoría Crítica, n 1, 2009, p. $72-87$ y «¿Posibilitan las teorías sociales de Habermas y Honneth una crítica del capitalismo?», en Revista de Humanidades y Ciencias Sociales, $\mathrm{n}^{\circ} \mathrm{II}, 2012$, pp. 39-50. 
relación entre crítica e historicidad, en términos de una autorreflexión de la crítica que asuma sin restricciones su carácter histórico, se enfrenta al peligro, que se pone de manifiesto en diferentes niveles, del relativismo (III y IV). Para completar nuestro enfoque, resulta pertinente, por un lado, afrontar la concepción de la historicidad de dos autores, X. Zubiri e I. Ellacuría, que no aparecen vinculados ni a la hermenéutica ni a la corriente de la teoría crítica, pero que en su noción de lo formalmente histórico han articulado una idea normativa (y no ontológica) de historicidad que responde de una manera original al reto del relativismo histórico (V), por otro, referir al menos aunque sea muy brevemente la relevancia de la relación de la crítica con el pasado histórico, en concreto con las críticas realizadas en el pasado que no lograron su objetivo y quedaron sin efecto alguno (VI).

La cuestión de la historicidad ocupa un lugar claramente relevante en la obra de W. Dilthey ${ }^{9}$, Heidegger ${ }^{10}$ y Gadamer ${ }^{11}$. En la tradición hermenéutica, sobre todo en Heidegger (aunque se podría pensar también en Gadamer, a pesar de que su planteamiento no sea reductible al de aquél), la historicidad es pensada en relación a la existencia humana que cada uno de nosotros somos, es decir, en relación al ser humano individual (y no tanto en relación a la formación social). Cuando se afronta en el seno de la hermenéutica la cuestión de la historicidad, el ámbito considerado primordialmente es la historicidad de la existencia humana y no la historicidad de la realidad social: ésta sería un derivado de aquélla. Pero en esta tradición la historicidad no es concebida como el estar necesariamente condicionado un individuo por el contexto histórico en el que se ha formado como tal y en el que desarrolla su vida. La historicidad es pensada como modo de ser constitutivo del ser humano, como una de sus categorías ontológicas fundamentales. La historicidad no es concebida como el carácter histórico en cada caso concreto de los sujetos, sino como aquel modo de ser constitutivo suyo, condición de posibilidad de la historia real, fáctica, y de su conocimiento. La historicidad es pensada no en el plano de lo óntico, sino en el de lo ontológico.

Así, para Heidegger, «la pregunta por la historicidad es una pregunta ontológica por la constitución de ser del ente histórico». ${ }^{12}$ La historicidad es en Heidegger la condición de posibilidad ontológica de la historia y de su conocimiento: «La proposición «el Dasein es histórico» se acredita como un enunciado ontológico-existencial fundamental. No tiene el carácter de una mera constatación óntica del hecho de que el Dasein acontece dentro de una «historia universal». Ahora bien, la historicidad del Dasein es el fundamento de la posibilidad del comprender histórico, y éste, por su parte, lleva en sí la posibilidad de desarrollar de manera expresa la historia como ciencia.» ${ }^{13}$ La historicidad es el fundamento ontológico

9 Ver W. Dilthey: La construcción del mundo histórico, México, Fondo de Cultura Económica, 1944, pp. 171 y ss.

10 Ver M. Heidegger: Ser y tiempo, Madrid, Trotta, 2003, §74.

11 La relevancia de la cuestión de la historicidad en Gadamer se plasma en el papel central que en su obra más importante ocupa la categoría de «conciencia histórico-efectual», la cual es concebida como «conciencia de la situación hermenéutica», ver H.-G. Gadamer: Verdad y método, Salamanca, Sígueme, 1991, pp. 314 y ss. y 370 y ss.

12 Heidegger: Ser y tiempo, ed. cit., p. 417.

13 Ibid., p. 349. 
del Dasein en cuanto tal, el modo de ser de su acontecer: «El carácter de la historicidad es previo a lo que llamamos historia (el acontecer de la historia universal). La historicidad es la constitución de ser del «acontecer» del Dasein en cuanto tal, acontecer que es el único fundamento posible para eso que llamamos la «historia universal», y para la pertenencia histórica a la historia universal.» ${ }^{14} \mathrm{El}$ «adelantarse hasta la muerte», la «resolución precursora», la presentación de la tradición como legado de posibilidades de existencia, la «repetición» de aquellas posibilidades trasmitidas por la tradición que el Dasein elige hacer propias, el «destino» y el «destino común» definen la «historicidad propia», conforman las determinaciones fundamentales de la historicidad del Dasein en cuanto tal. ${ }^{15}$

Gadamer, por su parte, formulado muy sintéticamente y sin pretensión de ser exhaustivo, concibe la historicidad a partir de la noción de conciencia histórico-efectual. Esta conciencia, que sería la propia del intérprete reflexivo, se sabría a sí misma como perteneciendo constitutivamente al acontecer de la tradición en cada acto de interpretación y comprensión de los productos culturales. Este acontecer tendría la forma de una mediación de la tradición consigo misma: en cuanto mediación de la historia efectual de las obras de cultura y los prejuicios del intérprete, transmitidos a su vez por la tradición. «El comprender debe pensarse menos como una acción de la subjetividad que como un integrarse en el acontecer de la tradición, en el que pasado y presente se hallan en continua mediación» ${ }^{16}$.

En la hermenéutica, por tanto, la historicidad, en cuanto que dimensión ontológica constitutiva del sujeto histórico, es la condición de posibilidad de lo histórico fáctico y de su comprensión. Es cierto que se produce en la hermenéutica un llamado fundamental a hacerse cargo de la historicidad por parte del individuo, del Dasein o del intérprete. Esto lo ha mostrado Ortega en relación a Dilthey, para el cual, por un lado, «la filosofía es (...) «una predisposición y una necesidad» que nos encontramos en nuestra propia conciencia» $\mathrm{y}$, por otro, «la conciencia de nosotros mismos (...) es histórica». ${ }^{17}$ De aquí se sigue que «esa clara conciencia de la propia historicidad obliga (...) a reconocer que la primera tarea filosófica (...) consistirá a elevar aquella necesidad y predisposición existentes en el sujeto a plena y concreta conciencia de su lugar histórico.» ${ }^{18}$ Es decir, implica que «la primera labor del filósofo sea hacerse cargo de cuál es la situación histórica en la que está.» ${ }^{19}$ Este llamado a hacerse cargo de la propia historicidad, en los términos de la asunción de la propia situación hermenéutica, la cual es una situación histórica, aparece al comienzo de buena parte de las lecciones impartidas por Heidegger desde 1919 a 1930. El esfuerzo de apropiación de la propia situación histórica es aquí el punto de partida para poder confrontarse con la problemática filosófica fundamental para nosotros, una problemática definida precisamente a partir de la problematicidad del presente mismo que vivimos. ${ }^{20}$ Un llamado tal cabe ser reconocido también en la teoría crítica de Horkheimer y Marcuse en relación a la apropiación

14 Ibid., p. 43.

15 Ibid., pp. 398-407.

16 Ver Gadamer: Verdad y método, ed. cit., p. 360.

17 J. Ortega y Gasset: Goethe, Dilthey, Madrid, Alianza editorial, 1983, p. 188.

18 Ibid., pp. 188-9.

19 Ibid., p. 189.

20 Sobre esto ver el estudio, ya clásico, de Ramón Rodríguez La transformación hermenéutica de la fenomenología, Madrid, Tecnos, 1997. 
por parte del teórico del interés histórico que impulsa su labor, de la situación histórica en la que interviene y de la función social de su praxis teórica. Aunque resulta tentador ver aquí una influencia de la hermenéutica en la teoría crítica (concretamente de Dilthey en Horkheimer y de Heidegger en Marcuse) $)^{21}$, resulta patente que tal llamado a la autorreflexión de la teoría puede encontrarse en la tradición teórica materialista posterior a Hegel y encuentra ya en Marx plena plasmación. ${ }^{22}$

Sin embargo, el concepto ontológico de historicidad no sólo no es útil para clarificar el estatuto de la crítica sino que resulta problemático para ésta desde un punto de vista filosófico-político. En tal concepto ontológico de historicidad se dejó enredar el intento del primer Marcuse de realizar una síntesis entre hermenéutica del Dasein y materialismo histórico, lo que él denominó una «fenomenología dialéctica» ${ }^{23}$ y lo que acabó orientando su primer proyecto teórico en una dirección ontológica, que tuvo que dejar atrás para que su trabajo filosófico pudiera realizar una contribución al proceso de fundamentación de una teoría crítica de la sociedad junto con Horkheimer en los años treinta en Nueva York. El caso del primer Marcuse permite poner de manifiesto la problematicidad del concepto ontológico de historicidad para la teoría crítica. En primer lugar, hablar de una historicidad ontológica, que incluiría una serie de estructuras fundamentales, va de la mano en Marcuse (como fue el caso en Heidegger) de la afirmación de la posibilidad de un acceso a tal dimensión ontológica humana: supone la postulación de una filosofía entendida como ontología fundamental del modo de ser constitutivo del ser humano. La pretendida radicalidad de la concepción ontológica de la historicidad (puesto que, efectivamente, tal concepción ontológica se concibe a sí misma como cualitativamente más radical que los afrontamientos meramente ónticos de la historicidad) desemboca paradójicamente en la defensa de una filosofía en sentido tradicional como es la ontología fundamental, a saber, como filosofía liberada, en tanto que filosofía pura, teorética, de todo interés óntico (es decir, ético-político), y desligada de los avatares de lo histórico y del conflicto de perspectivas socio-culturales-políticas existente en la historia efectiva: en definitiva, como liberada de toda historicidad. ${ }^{24}$ Además, con el concepto

21 Ver Th. Fath: Der frühe Horkheimer und Dilthey. Eine Untersuchung zur Konstitutionsphase der Kritischen Theorie, Frankfurt a. M., Peter Lang, 2006 y J.M. Romero (ed.): H. Marcuse y los orígenes de la teoría crítica, Madrid, Plaza y Valdés, 2010.

22 Véase, por ejemplo, K. Marx: «Introducción», en id., Líneas fundamentales de la crítica de la economía política (Grundrisse), Barcelona, Crítica, 1977, pp. 5-36.

23 H. Marcuse: «Contribuciones a una fenomenología del materialismo histórico», en: J. M. Romero (ed.): $H$. Marcuse y los orígenes de la teoría crítica, ed. cit., pp. 105-114.

24 Ver sobre esta temática mis trabajos «Herbert Marcuse y los orígenes de la teoría crítica. Una aproximación», en J.M. Romero (ed.): H. Marcuse y los orígenes de la teoría crítica, ed. cit., pp. 7-79 y «¿Entre Marx y Heidegger? La trayectoria filosófica del primer Marcuse», en H. Marcuse: Entre hermenéutica y teoría crítica. Artículos 1929-1931, Barcelona, Herder, 2011, pp. 7-37. La evolución de la posición filosófica de Marcuse desde su primer periodo como asistente de Heidegger (de 1928 a 1932) a su etapa posterior como principal colaborador filosófico de Horkheimer en Nueva York (de 1934 a 1938) sólo fue posible a partir de una profunda cesura, biográfica e intelectual, causada por los acontecimientos de 1933, fundamentalmente la experiencia del exilio y el shock sufrido por la toma de partido de Heidegger en favor del nacionalsocialismo. El camino de Heidegger a Horkheimer recorrido por Marcuse tuvo como condición el abandono por parte de éste del proyecto de una ontología fundamental de la existencia histórica, que pretendía servir de fundamento filosófico para un materialismo histórico renovado en sus energías críticas. A pesar de las referencias a Heidegger en las obras posteriores de Marcuse, implícitas en Eros y civilización y explícitas en El hombre unidimensional, lo que define el decurso maduro del pensador berlinés es el abandono de toda concepción ontológica de la historicidad y su esfuerzo por 
ontológico de historicidad se pretende aludir a una dimensión de lo humano que, a pesar de recibir el nombre de historicidad, hace referencia a algo que no es histórico ello mismo, sino condición de posibilidad de toda historia fáctica real. ${ }^{25}$ La historicidad del ser humano remitiría a estructuras, modos de ser, inherentes al ser humano en cuanto tal (abriéndose así la puerta a una lectura antropológica de la historicidad como definidora del ser humano en cuanto que ser constitutivamente histórico) y que cabría explicitar a través de ese acceso elevado por encima de toda historicidad que es el plasmado en la ontología fundamental.

Estamos efectivamente ante una paradoja: la condición de posibilidad de la historia real, fáctica, reside más allá de la historia, en la constitución ontológica (¿antropológica?) del ser humano y sería cognoscible mediante una disciplina de conocimiento ubicada por encima de todo perspectivismo y relativismo históricos. En esto se pone de manifiesto las consecuencias perversas de pretender pensar algo así como lo constitutivo de lo histórico a partir de una reflexión ontológico-trascendental sobre sus condiciones ontológicas de posibilidad (que, según tal estrategia de pensamiento, no pueden ser concebidas como históricas ellas mismas). El problema de la categoría de historicidad de la hermenéutica es por lo tanto su articulación en el seno de un proyecto filosófico ontológico-trascendental, que pretende explicitar las condiciones ontológico-trascendentales de posibilidad de algo radicalmente marcado por la contingencia y la facticidad como es lo histórico. De ello resulta una transfiguración de tal ámbito en forma de un concepto que, incapaz por definición, por su pretensión ontológico-trascendental, de hacerse cargo de lo contingente y fáctico de lo real-histórico, lo convierte en un componente más de la constitución ontológica de la existencia humana, la cual, siendo ahistórica, posibilitaría lo histórico. Esta paradoja fue ya denunciada por la teoría crítica ${ }^{26}$. Esta no desemboca en un planteamiento ontológico en el sentido de Heidegger, pues carece de toda pretensión de investigar las presuntas estructuras fundamentales de la existencia en cuanto tal, en las que no cree: su ámbito es lo histórico real y forma parte de su labor la realización de un trabajo de historización de lo que en el plano histórico aparece como habiendo adquirido una consistencia definitiva, un estatuto consolidado no historizable (como es el caso de lo que reclama para sí poseer un estatuto ontológico). Respecto a las estructuras del Dasein investigadas por Heidegger, el primer Habermas reclamó «el reconocimiento, propio del «materialismo», de que esas mismas

comprender críticamente las sociedades industriales desarrolladas del siglo XX y el modo de estar en el mundo el ser humano producido por ellas. Para la evolución de Marcuse resulta aclaradora una entrevista concedida por él unos años antes de su muerte: «Heidegger's Politics: an Interview with Herbert Marcuse by Frederick Olafson», en Graduate Faculty Philosophy Journal, Vol. 6, № 1, 1977, pp. 28 y ss.

25 Sería posible otorgar un estatuto ontológico a aquellos elementos de la existencia humana a partir de los cuales y en relación a los cuales se define el respectivo modo de ser de los entes. Dicho así, podrían poseer tal carácter ontológico aspectos de la existencia humana propiamente históricos, de manera que sería la particular configuración histórica del Dasein lo que definiría de una manera determinada (evidentemente, histórica) el modo de ser con el que se presentan en cada caso los entes. Esta no es la posición de Heidegger en Ser y tiempo, para el que los existenciarios no son históricos, sino constitutivos del Dasein en cuanto tal (de ahí la tentación de una interpretación antropológica de la ontología del Dasein). Agradezco a Noé Expósito y a Jordi Magnet sus indicaciones sobre esta temática.

26 Ver H. Marcuse: «Philosophie des Scheiterns: Karl Jaspers' Werk», en H. Saner (ed.): Karl Jaspers in der Diskussion, Múnich, Piper Verlag, 1973, pp. 125-132 y, del mismo autor, «German Philosophy, 1871-1933», en R. Wolin y J. Abromeit (eds.): Heideggerian Marxism, Lincoln y Londres, University of Nebraska Press, 2004 , pp. 151-164 y Th. W. Adorno: Actualidad de la filosofía, Barcelona, Paidós, 1991. 
estructuras existenciarias analizadas a nivel trascendental se hallan también determinadas por el proceso histórico real, en lugar de preceder al mismo. La propia historicidad es un producto de la historia, de la historia real». ${ }^{27} \mathrm{La}$ problematicidad política del concepto ontológico de historicidad reside aquí: en que instaura en condición de lo histórico-óntico algo que no es histórico ello mismo y que sería constitutivo de lo humano, con lo cual naturaliza tales condiciones ontológicas, que quedan situadas más allá de toda crítica y de toda posibilidad de transformación práctica. ${ }^{28}$

\section{II}

Más allá de la problemática deriva ontológica aquí apuntada, puede sostenerse que la concepción de la crítica en el seno de la teoría social crítica debe partir, como postula en general la hermenéutica, de la asunción consecuente del significado de la historicidad: pues en ello se jugaría su alcance y radicalidad. Pero la asunción de la historicidad no conduce en la teoría crítica de la sociedad a ontologizarla, sino a extraer de la misma todas sus implicaciones epistemológico-políticas. Tal como ha expuesto E. Renault, esta idea puede rastrearse ya en Marx: «una de las tesis fundamentales del criticismo de Marx» es que «la crítica de lo real debe acompañarse de una interrogación sobre su propia historicidad.» ${ }^{29}$ Ello es palpable en el Marx maduro: «La crítica de la economía política es la consumación de la historización marxiana de la crítica. Ella presupone la historización del tema de la crítica (no se trata ya de una crítica externa, sino de la crítica interna que exhibe las contradicciones del capitalismo), de la forma de la crítica (El Capital expone la verdad de su objeto procediendo al examen de las condiciones históricas de la validez de esta exposición) y de su objeto (éste no es ya la religión o la política, sino el nivel de la historia real: la economía). Estas historizaciones adquiridas en 1843 son ahora completadas con las de la materia y el sujeto de la crítica.»30 Esta problemática aparece expresamente en el primer Marcuse («el marxismo es una teoría histórica en un doble sentido: por un lado, porque su objeto es histórico y es tratado como histórico y, en segundo lugar, porque él mismo interviene en el movimiento histórico en una

27 J. Habermas: Teoría y praxis, Madrid, Tecnos, 1990, p. 406.

28 La referida problematicidad política de tal concepción de la historicidad se pone de manifiesto de manera palpable en la confrontación de R. Koselleck con la concepción de la historicidad de Heidegger y Gadamer, que desemboca en su propuesta de una Histórica, cuya tarea sería establecer los conceptos trascendentales de toda historia posible y que acaba compartiendo la paradoja en la que cae la hermenéutica. En efecto, la Histórica concibe como conceptos transcendentales respecto de toda historia (futura) posible pares categoriales del tipo de amigo-enemigo, público-secreto, tener que morir-poder matar, amo-esclavo. Estos pares categoriales definirían pues la historicidad humana y establecerían las condiciones de posibilidad de la historia real. Pero esta confrontación de Koselleck con Heidegger y Gadamer no lleva demasiado lejos de un planteamiento ontológico, pues la postulación de tales categorías como trascendentales respecto de la historia posible no hace sino naturalizarlas (y, con ello, de hecho, ontologizarlas) como elementos inherentes de la historia humana, también de la historia por hacer, con lo que restringe de manera sangrante la capacidad de los sujetos para criticar con pretensión de transformación importantes ámbitos de la realidad histórica existente. Ver sobre esto R. Koselleck y H.-G. Gadamer: Historia y hermenéutica, Barcelona, Paidós, 1997. Expongo mi aproximación crítica sobre este tema en «La histórica de Koselleck y la apertura de la historia», incluido en mi libro Crítica e historicidad, Barcelona, Herder, 2010, pp. 73-92.

29 E. Renault: Marx et l'idée de critique, París, PUF, 1995, p. 31.

30 Ibid, p. 120. 
situación histórica concreta» ${ }^{31}$ ) y alcanza adecuada plasmación en Horkheimer en su periodo de Nueva York: «la teoría crítica persigue de forma plenamente consciente, en la formación de sus categorías y en todas las fases de su desarrollo, el interés en la organización racional de la actividad humana» ${ }^{32}$. Por ello, la teoría crítica se comprende a sí misma «como momento de una praxis que apunta a nuevas formas sociales $»^{33}$.

La tesis que quiero defender es que la crítica alcanza su máxima radicalidad cuando se apropia de su historicidad concreta, es decir, cuando asume su objeto, la realidad social, como histórico, pero también cuando asume que tanto el sujeto de la crítica como sus herramientas teóricas y sus propios parámetros normativos también lo son. Veamos esto por partes. Esto significa, en primer lugar, el mantenimiento de la conciencia de la historicidad de su objeto, de la realidad social que pretende poner en cuestión, de modo que quede excluida toda concepción de la misma como legalidad, consolidación o diferenciación ya no historizable: la crítica no puede dar por válido ningún estado de cosas histórico considerado como definitivo o no superable y como blindado respecto de toda intervención práctica transformadora. Esto vale sobre todo para el ámbito de la economía, que ha llegado a presentarse como una dimensión definida por una legalidad propia que se impone a la capacidad de decisión democrática en la forma de presuntos imperativos que no se pueden rechazar ni soslayar. Pero también la realidad institucional aparece para la crítica como moldeable históricamente. Lo mejor de la teoría crítica ha sostenido que tal constatación tiene que ir de la mano de la convicción de que las transformaciones a realizar deben someterse al principio de una prudencia consciente de la complejidad de los efectos de las intervenciones políticas que se llevan a cabo en el marco de los proyectos de transformación, los cuales deben estar sustentados, por un lado, en un concepto reflexivo de justicia y, por otro, en la movilización activa de las mayorías que sufren el desorden imperante.

En segundo lugar, significa que la teoría crítica asuma que el marco teórico en que se realiza está caracterizado también por su historicidad, es decir, primero, que es fruto de un desarrollo interno del campo de la teoría y la ciencia social, segundo, que su punto de partida para la reflexión es en cada caso el decurso histórico real acaecido y la situación social vigente y, en definitiva, que está vinculado a los esfuerzos sociales, externos a la teoría, por comprender la realidad social en su problematicidad con objeto de confrontarse con ella prácticamente. La teoría crítica aparece así no como un corpus cerrado de tesis teóricas de carácter pretendidamente indiscutible, sino como un esfuerzo continuamente renovado de comprensión del régimen socio-económico vigente al hilo de sus transformaciones, orientado por las problemáticas que conmueven el momento presente, de cara a sustentar, respaldar e ilustrar una respuesta práctica a las mismas: es decir, forma parte de una tradición de ilustración y aclaración teórica de la realidad social con una pretensión práctico-política.

En tercer lugar, significa que el agente de la crítica asuma su propia historicidad, es decir, su propio carácter histórico, su estar ubicado en una determinada situación histórica definida por unos conflictos y escisiones específicos, su estar en un determinado horizonte de problemas propio del momento histórico que le ha tocado vivir. De todo ello se deriva

31 Ver Marcuse: «Contribuciones a una fenomenología del materialismo histórico», en J.M. Romero (ed.): $H$. Marcuse y los orígenes de la teoría crítica, ed. cit., pp. 105-6.

32 Ver sobre todo Horkheimer: Teoría tradicional y teoría crítica, ed. cit., p. 80.

33 Ibid., p. 51. 
que a la crítica (y, por extensión, a una teoría crítica) le es inherente el estar ubicada en una determinada toma de posición respecto a los antagonismos y conflictos existentes. Esto no implica colocar en la base de la crítica una toma voluntarista y decisionista de posición, en sí injustificable y que por lo tanto bien podría haber sido la contraria. Es cierto que la crítica y la teoría crítica implican por parte del crítico y del teórico crítico el estar ya ubicado de una determinada manera respecto a los antagonismos dados. Pero esta ubicación tiene como base el proceso de socialización de los sujetos, que se juega en un doble plano: por un lado, su socialización en el grado de desarrollo moral y político plasmado en la vida social e institucionalizado en su respectiva formación social y, por otro, su socialización en una particular cultura política, de entre las que se enfrentan en el marco social. Este doble proceso de socialización, que contiene un aspecto claramente generacional, pero en el que es relevante tanto la posición social de los sujetos como las derivas biográficas particulares, conforma a los individuos como ya siempre posicionados moral-políticamente ante la realidad social, como habiendo asumido ya siempre una determinada perspectiva moral-política ante lo social. En el caso del teórico crítico, este llega a actuar reflexivamente como tal cuando es capaz de comprender su labor como inscrita en el seno de una determinada tradición de esfuerzos y luchas en pos de la comprensión, crítica y transformación de la realidad en una dirección justa.

Respecto a esta concepción del proceso de socialización político-moral de los sujetos, puede sostenerse lo que L. Kohlberg afirmó respecto al desarrollo moral: que los parámetros del juicio moral son algo en lo que el individuo es en principio socializado, pero al llegar a determinado momento de madurez personal, cognitiva y moral, los individuos están en condiciones de confrontarse con este momento de facticidad (si no por entero, sí con aspectos relevantes del mismo) que los constituye y pueden iniciar un proceso de problematización o, en su caso, de justificación racional y argumentada de su posicionamiento frente a la realidad social. ${ }^{34}$ En determinados casos, la profundidad de la problematización puede llegar a ser tal que de ella se derive la reformulación profunda de la propia posición ético-política de partida, pero en ningún caso estaríamos ante una decisión libre, abstracta e infundamentable entre visiones inconmensurables del mundo o entre valores, tal como planteó M. Weber. ${ }^{35}$ La justificación de determinados parámetros político-morales en los que hemos sido socializados o su problematización sólo puede realizarse en cada caso en virtud de lo que se es capaz de defender argumentativamente ante los demás como justo.

\section{III}

Del papel reclamado aquí para la historicidad en el seno de la crítica se derivan sus supuestas implicaciones problemáticas: el que ello implique a su vez la necesidad de asumir la historicidad de sus parámetros normativos. El peligro que asoma aquí es el del relativismo. Si los parámetros normativos de la crítica son históricos y se modifican con el tiempo, ¿cuál es el criterio para realizar una crítica que trascienda sus condiciones históricas?

34 La teoría de Kohlberg sobre los estadios de desarrollo del juicio moral trató de hacerse cargo de este proceso, que caracteriza según él, el tránsito desde un estadio moral convencional a uno postconvencional. Ver R. Hersch, J. Reimer y D. Paolitto: El crecimiento moral. De Piaget a Kohlberg, Madrid, Narcea, 1997.

35 Ver M. Weber: El político y el científico, Madrid, Alianza, 1992, pp. 215-6. 
¿Puede la crítica reclamar una validez que supere los límites de su contexto de surgimiento y constitución? ¿Por qué se afirma que la crítica se juega su radicalidad en la asunción de su historicidad? ¿No reside aquí, en la historicidad de sus parámetros normativos, la raíz de su debilidad, el principio de su desfundamentación?

Me centro aquí en el posible relativismo derivable de la historicidad, y no el que pueda resultar de la diferencia cultural, del que no puedo ocuparme en el contexto de la presente discusión. Respecto a esto debe sostenerse, por un lado, que no hay que temer en exceso al fantasma del relativismo, al menos en su alcance histórico, a saber, entendiéndolo como la relatividad de los juicios y valoraciones respecto a los parámetros normativos disponibles en el momento histórico en que son realizados. Esta es nuestra situación de hecho, los principios normativos válidos para nosotros ostentan un claro carácter histórico. Pero esta conciencia histórica no impide que nuestra experiencia de un principio normativo como válido implique que lo consideremos vinculante para toda posición que se pretenda normativa futura y pasada. Efectivamente, en primer lugar, aquellos parámetros normativos que se asumen como válidos se presentan como debiendo ser tenidos como tales por toda crítica realizable con pretensión de validez en el futuro (es decir, la convicción de que determinado principio es justo implica que se lo considere válido para toda posición normativa futura). Es cierto que no puede cerrarse la posibilidad de que lo que consideramos hoy como justo sea corregido o reformulado en el porvenir y de que en consecuencia surjan o se constituyan parámetros normativos históricamente nuevos. Pero esta posible corrección, reformulación o incluso refutación de nuestros parámetros normativos y la posibilidad del surgimiento de nuevos parámetros sólo puede ser pensada por nosotros como constituyentes de un nuevo horizonte normativo si ello implica una ampliación y un enriquecimiento de lo que para nosotros vale como normativo y que, por factores históricamente indisponibles para nosotros y que constituyen nuestra facticidad histórica, quedan fuera de nuestro horizonte visual, por llamarlo de alguna manera. Es decir, de la historicidad de los parámetros normativos no se deriva un relativismo hacia el futuro, pues en tanto que ubicados en nuestra posición normativa no tenemos más remedio que valorar las transformaciones posibles como un avance o, en su caso, como una involución respecto a lo que consideramos válido. Con esto no estoy defendiendo una visión progresista de la historia, en el sentido de que en la historia se esté produciendo un efectivo progreso moral: de lo que se trata es que a la hora de representarnos y confrontarnos con posibles cambios en el marco normativo en el que nos encontramos, sólo podemos aceptar como cambios normativos lo que constituya una ampliación o enriquecimiento de lo que para nosotros hoy aparece como normativo, sin que con ello estemos afirmando la existencia de una dinámica histórica efectiva de ampliación y enriquecimiento del marco normativo en el que nos encontramos.

En segundo lugar, tal historicidad no implica que se tengan que dar por buenos todos los comportamientos, leyes o instituciones del pasado que supuestamente fueron tenidos entonces como válidos, pero que ahora aparecen como aborrecibles, como es el caso de la esclavitud. En este caso concreto, lo cierto es que tanto en el mundo antiguo como en el moderno, a pesar de la institucionalización oficial de la esclavitud en numerosas sociedades, se elevaron voces y sobre todo se produjeron levantamientos contra la misma exigiendo su abolición a partir de razones defendidas como consistentes. El hecho de que ello ocurriera permite afirmar que los defensores de la esclavitud podrían haber valorado y actuado de otra 
forma, puesto que en su época estaban ya disponibles (aunque no fueran socialmente dominantes y carecieran de institucionalización) los parámetros normativos y de racionalidad que lo posibilitaban. Esto es válido también para nuestro presente: hoy en día encontramos una multiplicidad de voces críticas y de lo que Foucault denominó «contraconductas» ${ }^{36}$ que son de continuo desprestigiadas y marginalizadas por las posiciones hegemónicas y que carecen de toda plasmación institucional. Es posiblemente en esas voces, en tales contraconductas, donde se estén consolidando parámetros normativos que darán lugar quizá a una figura más compleja y más rica (para determinadas perspectivas sociales hoy irrepresentable e incluso indeseable) a los movimientos socio-políticos críticos en el porvenir. Esto da la clave además de una idea importante para nuestro asunto, que es la de la pluralidad e interna conflictividad del marco normativo de cada época. Los parámetros normativos no son en cada época algo homogéneo y monolítico, sino que están marcados por una heterogeneidad y un antagonismo derivado de los antagonismos y escisiones reales. Naturalmente que en cada periodo histórico hay que hablar de parámetros normativos dominantes o hegemónicos, pero ello no agota en ningún caso la diversidad de parámetros normativos efectivos en posiciones éticopolíticas antagónicas a la dominante en cada momento histórico.

Pero aun en el caso de que en un pasado determinado no se elevara ninguna voz, ninguna resistencia contra acciones o instituciones que hoy nos parecen aberrantes, no cabe de ello deducir la inevitabilidad del relativismo. De hecho, no nos comportamos como relativistas cuando valoramos críticamente situaciones del pasado que en su momento no recibieron rechazo por parte de sus contemporáneos. Y este comportamiento es legítimo en tanto que seamos capaces de argumentar con razones que pretendemos de peso por qué tal situación del pasado resulta moralmente intolerable y podemos explicar por qué la perspectiva moral dominante en aquel pasado resulta más limitada, más restringida que la nuestra. Esta capacidad de argumentar mostrando los aspectos en que nuestra perspectiva moral es más amplia e incluyente que una determinada valoración moral del pasado legitima nuestro enjuiciamiento de la misma.

\section{IV}

Ocupémonos ahora de la cuestión del posible relativismo de la definición de la historicidad como constitutiva del proceso de formación de los parámetros normativos. Respecto a esto, resulta convincente la tesis de Honneth de que la fuente de los parámetros normativos que sustentan la crítica social hoy en día se encuentra en los conflictos sociales y políticos acaecidos a lo largo del pasado en nuestro ámbito socio-cultural y que forman hoy parte de lo que podríamos denominar nuestro bagaje político-moral, conflictos que poseen un componente normativo claramente moral. ${ }^{37}$ En los conflictos relevantes desde un punto de vista normativo, un grupo social que se ha sentido dañado en su dignidad, integridad, autorrespeto y en la satisfacción de sus necesidades fundamentales a causa de una determinada situación, regla de juego social, ley o decisión gubernamental o comportamiento de otros grupos, se

36 Ver M. Foucault: Seguridad, territorio, población, Buenos Aires, Fondo de Cultura Económica, 2006, pp. 225 y ss. y 236 y ss.

37 Ver A. Honneth: La lucha por el reconocimiento, Barcelona, Crítica, 1997, pp. 193-205. 
enfrenta a ellos elevando a conciencia y confiriendo realidad social en el ámbito intersubjetivo a la idea de la propia dignidad y a la exigencia de un trato y de una situación dignas. ${ }^{38}$ Como sostuvo Rosa Luxemburg, la «lucha de clases despierta el respeto de sí mismo, el heroísmo y la fuerza moral de las masas populares». ${ }^{39}$ Lo que la experiencia negativa del daño y la injusticia hace salir a la luz es una expectativa moral, que se pretende fundada y legítima, respecto a los otros sujetos concretos y a la sociedad en su conjunto. El taller en que se fabrican los ideales morales, del que despectivamente habló Nietzsche, ${ }^{40}$ se encuentra precisamente ahí: en ese proceso en el que la experiencia de daño recibido se interpreta no ya como daño meramente individual o como un destino social, sino como una experiencia que se sufre en virtud de la pertenencia a un determinado colectivo y de la ubicación en una determinada posición en el marco de un contexto de asimetrías, antagonismos y conflictos sociales. Esta reinterpretación de la vivencia individual en términos colectivos y sociales desencadena que la experiencia del daño se torne experiencia de injusticia compartida ${ }^{41}$. Va a ser esta experiencia negativa lo que va a provocar que cobre realidad social, se convierta en factor efectivo en la interacción social y aparezca como principio normativo legítimo en la interacción lo que hasta ese momento tenía un estatuto difuso no tematizado, como es el caso de la propia dignidad, al que a partir de entonces se puede acudir para sustentar las propias exigencias de trato justo, igualitario, digno. Reyes Mate ha sostenido también de manera expresa «el primado de la experiencia de la injusticia» a la hora de elaborar una teoría de la justicia. Ello significa que «hay sentimiento de injusticia sin teoría previa de justicia». Esto es fundamental, pues posibilita sostener que la experiencia de la injusticia no sólo tiene «prioridad histórica» sobre la concepción de la justicia, en tanto que «desencadena la reflexión sobre la justicia», sino también «prioridad lógica», en tanto que «los significados de justicia se encuentran en el interior de la experiencia de injusticia».42 Horkheimer apuntó en esta dirección cuando sostuvo que la desigualdad social ha provocado históricamente «una determinada reacción humana» que «exigió la supresión de la desigualdad». Sería la experiencia de lo intolerable lo que desencadena la formulación expresa de pretensiones de validez morales: «los elementos morales que empujan hacia adelante (...) se crean continuamente bajo la fuerte presión que pesa sobre una gran parte de la sociedad actual». ${ }^{43}$

Estos procesos de lucha social, impulsados por los humillados y ofendidos, pueden llegar a convertir en socialmente influyentes determinados principios fraguados en ellos como normativos e incluso provocar la institucionalización de algunos de tales principios como válidos socialmente. Estas luchas, además, pueden ser acumulativas y ello en un doble sentido: en cuanto que las institucionalizaciones a las que dan lugar pueden actuar de base para una ampliación posterior de las luchas y de sus objetivos y en cuanto que pueden servir de precedente y de referente simbólico para luchas posteriores, es decir, constituirse en tradición.

38 Sobre esto ver R. Forst: «Der Grund der Kritik. Zum Begriff der Menschenwürde in sozialen Rechtfertigungsordnungen», en R. Jaeggi y T. Wesche (eds.): Was ist Kritik?, Frankfurt a.M., Suhrkamp, 2009, pp. 150-164.

39 R. Luxemburg: Obras escogidas, Madrid, Editorial Ayuso, 1978, vol. 2, p. 82.

40 F. Nietzsche: La genealogía de la moral, Madrid, Alianza, 1972, pp. 53-4.

41 Ver A. Honneth: La sociedad del desprecio, Madrid, Trotta, 2011, pp. 55-73.

42 Ver R. Mate: Tratado de la injusticia, Barcelona, Anthropos, 2011, pp. 68-74.

43 M. Horkheimer: «Materialismo y moral», en id.: Materialismo, metafísica y moral, Madrid, Tecnos, 1999, p. 144. 
En un planteamiento de este tipo encuentra apoyo la concepción, que podemos atribuir a Habermas y Honneth, de que a posteriori puede reconstruirse en la historia acaecida de los conflictos y luchas sociales determinadas dinámicas que pueden ser calificadas de procesos de aprendizaje ${ }^{44}$. Pero, en todo caso, esto no debe implicar concebir el presente como culminación ya no superable de tales procesos de aprendizaje (¡como si ya no se pudiera aprender más!). Habermas ha sostenido con razón la idea de que la teoría crítica «tiene que orientarse por las posibilidades de procesos de aprendizaje, que queden abiertas con el nivel de aprendizaje históricamente ya alcanzado». ${ }^{45}$ Lo que no resulta legítimo es la restricción que efectúa la teoría de la sociedad moderna de Habermas de los procesos de aprendizaje posibles como incapaces de trascender la situación según él vigente de diferenciación sistémica. Es más bien al contrario: una de las labores centrales de la crítica y de una teoría crítica de la sociedad es el impulso de procesos de aprendizaje político-moral en los colectivos que sufren la estructura social vigente que apunten más allá de las restricciones impuestas por las reglas de juego capitalistas, restricciones que Habermas sintetiza en el concepto de imperativos sistémicos.

En el caso de Honneth, el concepto de proceso de aprendizaje aparece concretado en la idea de que en las luchas por el reconocimiento pasadas cabe reconstruir un movimiento tendente a la ampliación de los caracteres y propiedades individuales cuyo reconocimiento es exigido en las interacciones humanas y sociales y hacia la ampliación de los colectivos integrados en las relaciones de reconocimiento vigentes, institucionalizadas en el cuerpo social. Esta tendencia reconstruible da también la clave de qué transformaciones pueden considerarse en el presente como un progreso en el plano de las relaciones de reconocimiento y cuáles no ${ }^{46}$. Naturalmente, esto no implica comprometerse con la afirmación de una dinámica, objetiva e inherente a la historia, de progreso moral, sino sólo con que a posteriori y a partir de la posición moral en la que ya estamos podemos considerar determinada trama de procesos acaecidos como constituyendo un aprendizaje moral del que formamos parte nosotros mismos y en cuya realización exitosa estamos interesados.

Esto tiene diversas implicaciones: por un lado, los procesos de constitución de normatividad deben ser concebidos como procesos contingentes (dependen de la facticidad histórica, de conflictos y procesos de lucha social carentes de toda necesidad), procesos reversibles (caben estancamientos y retrocesos en el plano de las luchas sociales y en el modo en que se articula y plasma la crítica social, lo cual se traduce en retrocesos en el plano normativo) y como procesos abiertos (su posible dinámica reconstruible a posteriori desde nuestra posición normativa - en la dirección, por ejemplo, de la universalización de los derechos y de ampliación del número y cualidad de los derechos - no se orienta a ningún telos o fin determinado y ni mucho menos al presente pensado como realización de la normatividad pensable en cuanto tal).

Esto último permite sostener explícitamente, como ya se ha apuntado a lo largo del presente trabajo, que la radicalidad de la crítica se juega en la asimilación consecuente de su historicidad. Pues la conciencia de la historicidad de los parámetros normativos le permite al

44 Ver J. Habermas: La reconstrucción del materialismo histórico, Madrid, Taurus, 1981, pp. 9-44 y Honneth: La lucha por el reconocimiento, ed. cit., pp. 202-5.

45 J. Habermas: Teoría de la acción comunicativa, Madrid, Taurus, 1989, vol. II, pp. 541-2.

46 Ver N. Fraser y A. Honneth: ¿Redistribución o reconocimiento?, Madrid, Morata, 2006, pp. 141-8. 
crítico no restringirse ni fijarse a los valores e ideales ya institucionalizados en la sociedad moderna (como sería el caso, piensa Honneth de manera harto problemática, de los valores del mérito o rendimiento y de la libertad social en el ámbito de la acción social mediada por la institución del mercado $)^{47}$ como los únicos sostenes posibles de la crítica, y asumir como sustento válido de la crítica principios defendidos como normativos por determinados colectivos sociales pero que carecen de plasmación institucional relevante. Si la crítica sustentada únicamente en los valores ya institucionalizados tiende irremisiblemente a devenir una crítica meramente afirmativa del orden institucional vigente (una crítica que en cada denuncia de injusticias concretas refuerza el orden institucional en el que se plasma la normatividad a la que se remite), la crítica impulsada por principios que pretenden normatividad pero que carecen de toda institucionalización recibe de ellos el sustento para un cuestionamiento del orden institucional en cuanto tal: tal es el caso del principio, defendido por amplios colectivos como normativo, de la satisfacción de las necesidades fundamentales de los individuos y de los grupos sociales, que puede impulsar un cuestionamiento de la institución del mercado capitalista en cuanto tal. ${ }^{48}$

En resumen, puede afirmarse que para un marco social concreto, la fuerza de la crítica efectiva en el escenario social se sostiene en el tenso juego entre, por un lado, lo ya institucionalizado y lo socialmente ya consagrado como normativo a partir del modo en que se resolvieron las luchas pasadas y, por otro, el nivel y alcance de las luchas en marcha en el presente a partir de la correlación de fuerzas que se dan en él. El decaimiento, el estancamiento de las luchas sociales en un marco en el que la correlación de fuerzas está imponentemente en su contra, su incapacidad por ello para tener efectos hegemónicos, ni siquiera una influencia política mínimamente palpable, todo ello pone las condiciones para un retroceso de la fuerza de convicción y de la efectividad de la crítica en el plano social y un deterioro de las conquistas en el plano normativo: lo ya institucionalizado como normativo es hecho retroceder sin la presión y la efectividad de las luchas sociales vivas.

En relación a esto resulta relevante traer a colación la posible aportación de X. Zubiri y de I. Ellacuría a una concepción filosófica de la historicidad de tipo no relativista. Voy a centrarme aquí en una temática muy concreta, en la que se produjo una influencia efectiva de Zubiri sobre su discípulo, no pudiendo ocuparme adecuadamente de la complejidad de la metafísica intramundana de aquél, de la filosofía de la realidad histórica de Ellacuría ni de la dimensión teológica de ambas. ${ }^{49}$ En estos dos autores ${ }^{50}$ el término de historicidad

47 Ver ibid., pp. 107-148 y Honneth: Das Recht der Freiheit, ed. cit., pp. 317 y ss.

48 Desarrollo este tema en mi artículo «Sobre la pretensión de trascendencia de la crítica inmanente», en Diálogo filosófico, $\mathrm{n}^{\circ} 85,2013$, pp. 55-75.

49 Me ocupo con mayor extensión de los planteamientos de estos autores en los siguientes trabajos: «La historicidad de la crítica en X. Zubiri», «I. Ellacuría, una teoría crítica desde América Latina» (en Crítica e historicidad, ed. cit., pp. 93-124 y 205-230) e «Ignacio Ellacuría y la necesidad de autorreflexión de la teoría crítica», en ECA. Estudios Centroamericanos, Vol. 68, n 732, 2013, pp. 61-74.

50 Existe una clara continuidad entre la concepción de lo histórico de Zubiri y la de Ellacuría: este último utilizó ampliamente en la redacción de su obra sobre la realidad histórica el manuscrito, publicado póstumamente, de un curso de Zubiri sobre la dimensión histórica del ser humano. Ver X. Zubiri: Tres dimensiones del ser 
hace referencia primariamente a la historicidad humana: «La historicidad es, en efecto, una dimensión de este ente real que se llama hombre.» ${ }^{51}$ De hecho, distinguen entre la «historia» y la «historicidad individual de la existencia humana». ${ }^{52}$ En todo caso, sus reflexiones sobre lo formalmente histórico, es decir, sobre aquello que define propiamente lo histórico, pueden ser adoptadas como un enriquecimiento y una ampliación del concepto de historicidad hasta abarcar tanto el modo de ser del individuo que cada uno de nosotros es (como había hecho la tradición hermenéutica) como el ámbito de lo colectivo-social. Resulta relevante la aportación de Zubiri y Ellacuría si la entendemos como una concepción ampliada de la historicidad de carácter normativo (y no como constitutiva del ser humano en cuanto tal, como dan a entender los planteamientos de Heidegger y Gadamer), es decir, como remitiendo a lo que define y diferencia a lo histórico y a la historia respecto a otros modos de ser y de acontecer. Para estos autores, estamos ante un decurso propiamente histórico (a diferencia de otros decursos que poseen un carácter diferente) cuando nos encontramos con un proceso de capacitación y posibilitación: «los actos son «hechos históricos» tan sólo como realización de posibilidades. (...) Lo que en las acciones humanas hay (...) de histórico, es (...) la actualización, el alumbramiento u obturación de puras posibilidades.» ${ }^{53}$ Por ello, si cabe hablar de una dialéctica histórica, se trata en efecto de «una dialéctica de posibilidades».54 En definitiva, «sólo hay historia (...) cuando el hecho social es actualización de posibilidades y proyectos.» ${ }^{55}$

Lo propiamente histórico aparece caracterizado, por un lado, como un proceso de formación y de ampliación de capacidades en los sujetos a través de la sucesión de generaciones, al hilo de procesos de aprendizaje social de largo alcance institucionalizados en el cuerpo social y en marcha en los planos cognitivo y científico-técnico, moral y político. Tales capacidades nuevas quedarían sedimentadas tanto en la constitución de los individuos concretos de una generación como en el propio cuerpo social, en las disciplinas científicas, en el desarrollo tecnológico y productivo y en la estructura institucional. Al mismo tiempo, tal proceso de formación de nuevas capacidades plasmadas tanto en los individuos como en el cuerpo social modifica de tal modo la constitución de los sujetos y del propio cuerpo social que resulta transformado el poder subjetivo de apertura de nuevas posibilidades. La adquisición de nuevas capacidades determina simultáneamente la apertura de nuevas posibilidades. El proceso de capacitación transforma el principio de posibilitación definido por el conjunto de capacidades adquiridas por los individuos y plasmadas en el cuerpo social. Asimismo, la actualización, realización y apropiación de las posibilidades así abiertas, a partir de una

humano: individual, social, histórica, Madrid, Alianza editorial/Fundación Xavier Zubiri, 2006 e I. Ellacuría: Filosofía de la realidad histórica, San Salvador, UCA Editores, 1990.

51 X. Zubiri: Naturaleza, historia, Dios, Madrid, Editora Nacional, 1981 , p. 109. Para Zubiri en esta obra la historicidad del hombre consiste en que la realidad del hombre es de tal carácter que éste se relaciona consigo mismo siendo en un presente «lo que es, porque tuvo un pasado y se está realizando desde un futuro», ibid. Ver I. Ellacuría: «La historicidad del hombre en Xavier Zubiri», en id.: Escritos filosóficos, San Salvador, UCA Editores, 1999, vol. II, pp. 199 y ss.

52 I. Ellacuría: Veinte años de historia en El Salvador (1969-1989). Escritos políticos, San Salvador, UCA Editores, 1993, vol. I, p. 51.

53 Zubiri: Naturaleza, historia, Dios, ed. cit., pp. 327-8.

54 Ibid., p. 328.

55 Ibid., p. 331. 
elección ética y política efectuada a la luz de la consecución de la propia autorrealización, conduce a la incorporación por parte de los individuos y a la plasmación en el cuerpo social de tales posibilidades en forma de nuevas capacidades que modifican a su vez el principio subjetivo de posibilitación. Este círculo virtuoso definiría lo esencial de un proceso histórico en sentido propio.

Pero este proceso no debe ser entendido como un proceso mecánico que se desenvuelve según una lógica propia. Se sustenta en cambio en una determinada correlación de fuerzas en el plano social, es decir, son condiciones histórico-políticas concretas las que hacen posible o frustran en su caso el desarrollo del complejo proceso de capacitación y posibilitación que define para Zubiri y Ellacuría lo que podríamos denominar como historicidad propia. Tenemos aquí una concepción de la historicidad que no fija ninguna constitución de ser de la existencia expresable en categorías. La historicidad remite a un proceso en el que se constituye, históricamente, la realidad humana. Lo que en Heidegger aparece como la constitución ontológica del ser humano sería para Zubiri y Ellacuría algo constituido en cada caso en el seno de un proceso que es de carácter histórico. En Zubiri y Ellacuría la historicidad no es concebida como «la constitución de ser del «acontecer» del Dasein en cuanto tal» ${ }^{56}$, es decir en términos ontológicos en el sentido de lo que constituye el ser de la existencia humana. La historicidad caracteriza un proceso complejo y contingente en el que está en juego la realidad del ser humano, no sólo su ser. La historicidad remitiría a ese proceso, que sólo se da en condiciones históricas determinadas, en las que la transformación de la realidad humana en el sentido de su enriquecimiento y ampliación de capacidades va de la mano de la transformación práctica de la realidad circundante, natural e histórico-social, en el sentido de una plasmación en ellas de capacidades sociales colectivas, las cuales definen el principio de posibilitación histórica de cada formación social en un momento determinado.

Además, tal proceso es tematizable propiamente por una perspectiva moralmente interesada en la consecución de la autorrealización humana y no por un mero observador externo carente de interés. Esta caracterización del proceso que define lo propiamente histórico permitiría aclarar cómo la crítica puede llegar a ser (o dejar de ser) un factor activo en el proceso histórico. Pues la concepción de la historicidad de estos autores permite comprobar que, en los casos donde la reproducción del sistema social vigente exige, en virtud de coacciones estructurales como la defensa de la tasa de beneficio económico privado, la definición restrictiva de lo socialmente posible para la autorrealización colectiva, es decir, subordinándolo al objetivo de dicha reproducción, se abriría un desfase entre lo que las capacidades adquiridas por los sujetos y plasmadas en el seno del cuerpo social vigente permiten alumbrar como posible y la restricción social del ámbito de lo realizable según el criterio de la reproducción de lo dado (restricción que, en los términos de Marcuse, podría denominarse «represión excedente» $)^{57}$. Este desfase, que se traduce en una dolorosa experiencia de frustración y de impotencia ante lo vivido como intolerable a la luz de lo percibido como posible (y necesario de cara a la consecución de la autorrealización colec-

56 Heidegger: Ser y tiempo, ed. cit., p. 43.

57 H. Marcuse: Eros y civilización, Barcelona, Ariel, 1989, p. 53. 
tiva), aporta la base subjetiva y experiencial que sirve de soporte para la crítica social ${ }^{58}$. Un concepto como éste, ciertamente formal, de historicidad puede ayudar sin embargo a pensar la historicidad como no implicando necesariamente una posición relativista sino como definiendo unos criterios a cuya luz cabe tratar de pensar los procesos reales, y como tales investigables empíricamente, de formación (y, en su caso, de degradación) de la normatividad base de la crítica.

\section{VI}

Por último, hay que indicar aunque sea de manera muy breve un aspecto fundamental de la historicidad que hemos dejado para el final: en la apropiación por parte de la crítica de su historicidad concreta juega un papel esencial la memoria de las luchas pasadas y de los movimientos socio-políticos críticos del pasado. Y no porque así la crítica consiga percibirse como fruto de una evolución o como impulsada por un proceso progresivo de luchas. Pues desde el presente de retroceso social y democrático en que nos encontramos, las luchas y movimientos críticos del pasado se nos muestran en discontinuidad con nuestra situación: tales luchas y movimientos fueron derrotados en su momento y la situación de derrota actual constituye su segunda muerte (la de efectos más desastrosos). Por ello, la tarea de una crítica que aspire a apropiarse de su historicidad y agudizar la radicalidad de su oposición al mundo vigente consiste en ser capaz de insertarse e injertarse en la trama profundamente discontinua de episodios de lucha y movilización crítica contra el orden capitalista vigente. ${ }^{59}$ Debe efectuar lo que Habermas atinadamente denominó una «rememoración crítica de la tradición». ${ }^{60}$ En tal rememoración se pone en juego para la actividad crítica en marcha hoy la posibilidad de apropiarse del significado trascendente de los conceptos políticos que aparecen en la actualidad como normativos y que son asumidos por el régimen vigente para su legitimación. Conceptos como democracia, libertad y justicia, pueden llegar a convertirse en conceptos que ya no legitiman el régimen vigente sino que lo problematizan cuando logramos apropiarnos de su componente trascendente respecto a lo existente, componente que fue forjado en las luchas pasadas y sucumbidas por la emancipación que, sobre todo en la modernidad, adoptaron tales conceptos como estandartes orientadores de los esfuerzos transformadores. Ello imprimió a tales conceptos un significado político específico que, respecto a la institucionalización de

58 Tal concepción permite también iluminar las situaciones en las que se produce una crisis de la crítica como aquellas en que, a partir de la experiencia de la propia impotencia social o en virtud de una colonización subjetiva por las formas dominantes de autolegitimación social, los sujetos son incapaces de alumbrar posibilidades históricas que su nivel de capacitación y las capacidades sociales plasmadas en el cuerpo social permitirían realizar. Tales situaciones, que para estos autores, tienen un carácter históricamente estructural, fueron conceptuadas por ellos con la categoría de pecado histórico, ver Ellacuría: Filosofía de la realidad histórica, ed. cit., p. 590.

59 Esta es la temática fundamental de la producción teórica del último Benjamin. Me refiero más extensamente a esto en mi trabajo «Sobre la actualidad de Walter Benjamin», en Constelaciones. Revista de Teoría Crítica, $\mathrm{n}^{\circ} 2$ 2, 2010, pp. 367-371. Sobre las abiertas diferencias entre los modos de concebir la relación del intérprete y la tradición de benjamin y Gadamer, pueden verse mis trabajos «La idea de una hermenéutica de lo concreto en Benjamin y Adorno: ¿más allá de Gadamer?», en Thémata. Revista de Filosofía, no 32, 2004, pp. $159-171$ y «Una crítica cultural materialista», en Revista Anthropos: Huellas del conocimiento, $\mathrm{n}^{\circ} 225$ (número dedicado a: «Walter Benjamin: la experiencia de una voz crítica, creativa y disidente»), 2009, pp. 85-99.

60 Habermas: La reconstrucción del materialismo histórico, ed. cit., p. 114. 
tales conceptos en las sociedades democráticas desarrolladas, permanece como contenido no realizado (ni realizable), es decir, como contenido trascendente. Esta dimensión histórica de los conceptos políticos, esta genuina historicidad de los conceptos, que nos pone en condiciones de distanciarnos de su particular y restrictiva institucionalización en el régimen social vigente, sólo se torna asequible a esa rememoración de las luchas pasadas capaz de hacerse cargo de su carácter moralmente vinculante para nosotros, precisamente en una situación en la que nos encontramos en abierta discontinuidad con ellas. 
